\title{
Assessing the fikely Impacts of Proposed Food Boxes on SNAP Recipients
}

\author{
Ahoefa Ananouko
}

T

he Supplemental Nutrition Assistance Program (SNAP), formerly known as the Food Stamp Program, is the largest of the federal food and nutrition assistance programs. Studies show that SNAP is vital in increasing recipients' food budgets, as reflected in recipients' food spending before and after the 2009 Stimulus Package. SNAP has also been shown to reduce food insecurity for U.S. households. Proposed changes to SNAP by the Trump administration in its initial 2019 budget request could have major impacts on households that depend on the program to lessen the setbacks caused by poverty. Based on economic theory and results from previous studies examining expenditure responses to changes in SNAP, this article explores possible impacts of allocating half of SNAP benefits in the form of food boxes. It argues that these changes would have a negative impact on low-income households-especially children. These changes could create further food insecurity among some of the most vulnerable, while also increasing costs to the government. 


\section{BACKGROUND}

The Supplemental Nutrition Assistance Program (SNAP), formerly known as the Food Stamp Program, is the largest of the federal food and nutrition assistance programs in the United States. SNAP accounted for 69 percent ( $\$ 68$ billion) of all federal food and nutrition assistance spending in fiscal year (FY) 2017, which equaled $\$ 98.6$ billion. In comparison, the Women, Infants, and Children program (WIC) accounted for 5.7 percent and the National School Lunch program accounted for 13.8 percent of this spending (Oliveira 2018). By providing food purchasing assistance, SNAP supplements food budgets for low-income households. With the exception of hot foods for immediate consumption, formula, and vitamins, SNAP benefits can be used to purchase all food items.

During FY 2017, the program served about 42.2 million people, down 5 percent from FY 2016 (Oliveira 2018). Though most SNAP-receiving households are low-income, they are diverse in nearly all other aspects. Over half of participants are children, seniors, or persons with disabilities. Contrary to common misconceptions, the majority of SNAP recipients are working households (about 55 percent of households that received SNAP in 2016 had earnings) and only about 5 percent also received cash transfer public assistance such as Temporary Assistance for Needy Families (TANF) (U.S. Department of Agriculture [USDA] 2018).

The program now known as SNAP began as the Food Stamp Program (FSP) in 1961 as an eight-county pilot program, with the signing of Executive Order 10914 by then-President John F. Kennedy. The wide support it received was primarily due to a logrolling effort in Congress to retain subsidies for rural farmers. In 1962 and 1963, the pilot program expanded to 43 municipalities, the success of which led to the Food Stamp Act of 1964. This gave counties the option to voluntarily roll out the program. The Agriculture and Consumer Protection Act of 1973 was passed to require that states offer the program in all jurisdictions (USDA 2018).

Besides its name, the program has undergone changes throughout the decades since it was first implemented. The Food Stamp Act Amendment of 1970 brought changes such as uniformity of income and resource eligibility standards across the nation. The amendment also required that benefits be equivalent to the cost of a low-cost, nutritionally adequate diet, though what exactly constituted "nutritionally adequate" was not properly defined. It also reduced the amount households must pay to receive benefits. Previously, the law required recipients to purchase the "stamps." The change reduced the amount a household of four had to pay to receive benefits from 20 percent of its income to 16 percent. In 1977, the Food and Agriculture Act eliminated this requirement all together.

Another major change to SNAP was the move to allocate benefits through electronic benefit transfer (EBT). EBT is an electronic system that allows recipients to receive their government benefits in a debit card-like form, which can be used at any authorized 
retailer. Besides eliminating the need to print paper stamps, this helped reduce fraud and theft. During the Great Recession, the Obama administration passed the American Recovery and Reinvestment Act of 2009 (ARRA), more widely referred to as the stimulus package. This law provided a nearly $\$ 20$ billion increase in funds to SNAP that allowed for a temporary increase in benefits.

\section{HOW SNAP WORKS: THE MEANS-TESTED FORMULA}

SNAP is both a means-tested program and an entitlement program. Means-tested programs provide assistance to individuals below a designated resource threshold, whereas entitlement programs allow applicants to receive benefits as long as they qualify. SNAP serves millions of low-income households every month and operates through local offices by state public assistance agencies. The amount of benefits received by recipients depends on funding allocation and policies from Congress. All states follow the same basic provisions set forth by the federal government.

To be deemed eligible to receive benefits, households must meet certain criteria related to their income and resources. For SNAP, a household is defined as an individual or unit of individuals who live together in the same residence and purchase and prepare food together. A household's gross income-pre-tax wages and earnings-must be at or below 130 percent of the federal poverty line in order to qualify. Net income-the actual income a household brings home after all deductions have been made-must also be at or below the federal poverty level determined for that household in a particular fiscal year. Households with an elderly or disabled member are not subject to the gross income limit but are subject to the net income limit. Counted among a household's resources are cash income, money in a bank account, and some vehicles. States determine how to factor in the latter (Center on Budget and Policy Priorities [CBPP] 2018).

Some people are considered categorically eligible for SNAP benefits, which means they already qualify for other public assistance such as Temporary Assistance for Needy Families (TANF) or Supplemental Security Income (SSI). The specific dollar amount households receive is allocated according to the Thrifty Food Plan, a method designed by the USDA to estimate how much it costs to buy food to prepare nutritious, low-cost meals for a household. The USDA updates this estimate every year to keep pace with food prices.

\section{NEOCLASSICAL CONSUMER CHOICE THEORY AND SNAP}

Microeconomic theory provides a useful framework for understanding the spending decisions of SNAP recipients. In the neoclassical framework of consumer choice, a consumer's resources are allocated between one good or service and all other goods and services. The theory posits that in-kind transfers (such as SNAP) have the effect of increasing an individual's overall spending on goods and services, just as cash transfers 


\section{Featured Articles}

would. According to this theory, SNAP should increase overall spending on food and therefore, food consumption of recipient households. Because the transfer expands the household's total budget, a household's purchasing power is increased.

Traditional economic theory predicts that an increase in a household's food consumption would mirror an increase in its income if SNAP benefits provided less food than the household consumed before the transfer. But people rarely behave in the manner traditional economic theories predict. In their study of consumption responses to in-kind transfers, in which they analyzed the impact of the introduction of the FSP, Hoynes and Schanzenbach (2007) found that benefits allowed a significant increase in household food expenditures. Additionally, they found that because of the nature of SNAP (it can only be used to purchase food items, as opposed to TANF, which can be used for nearly anything), marginal propensity to consume (MPC) food also increased, especially in more disadvantaged households. Therefore, in the food stamp case there was minimal distortion to recipients' consumption choices compared to a cash transfer.

Further research by Beatty and Tuttle (2014), comparing food expenditure before and after an increase in SNAP benefits as a result of the 2009 stimulus package, found that consumption behavior did in fact change before and after the increase in benefits. They found that the stimulus increased average monthly household maximum benefits by about $\$ 80$ for a household of four and those households increased the share of their overall expenditures dedicated to food purchases. The value of this increase, however, steadily declined due to food price inflation being lower than projected. This caused food insecurity to rise among low-income households who received SNAP. Later cuts also continued to diminish benefit values, eventually leading to significant drops when the ARRA expired.

Taking a different perspective from traditional economics, Richard Thaler's (1980) behavioral economic theory of mental accounting posits that households use codes and categories to govern where their money goes. Essentially, the way a household categorizes and assigns the source of income determines how that income is allocated. Since most SNAP-receiving households only receive SNAP benefits (as opposed to also getting TANF or SSI), in addition to their earned income, that income source is allocated to food purchases automatically. Therefore, marginal propensity to consume food would fluctuate depending on SNAP benefit amounts. With these theories in mind, it is important to consider the effects of changes in the structure of SNAP on low- and noincome households.

\section{PROPOSED CHANGES}

The Trump administration's preliminary FY 2019 budget proposal contained what it considered to be "bold new approaches to administering SNAP." Although several changes were proposed, this analysis focuses specifically on those pertaining to benefits allocation. The proposal to have households who receive at least $\$ 90$ in benefits get 
a share of it in the form of USDA food packages would have altered the structure of SNAP significantly. Whereas all benefits are currently administered on the EBT card, the packages would comprise of items such as shelf-stable milk, ready-to-eat cereals, pasta, peanut butter, beans, and canned fruits and vegetables, as well as poultry or fish (Office of Management and Budget [OMB] 2018). The administration purported this modification would save taxpayers money and improve the nutritional value of foods consumed by recipients. In addition, the administration reasoned that this new structure would reduce the possibility of fraud, give states more latitude in designing a delivery system, and support the agricultural industry.

This aspect of the proposal resembles the former government-administered Commodity Distribution Program, the primary goal of which was to support farmers by removing surplus commodities from the market. In 1968, the Citizens' Board of Inquiry into Hunger and Nutrition determined this program to be a failure because it was "inadequate to promote the nutritional well-being of low-income persons" (Hoynes \& Schanzenbach 2007). Besides the limited items offered in the packages, there were logistical issues and the items often never made it to the people who needed them.

\section{IMPLICATIONS}

The primary purpose of the Trump administration's proposed changes to SNAP is to cut back on the costs of the program. Allocating portions of benefits in the form of food packages would lead to an estimated $\$ 213.5$ million reduction in funding for the program between 2019 and 2028 (OMB 2018). But the principle underlying goal may actually be to subsidize the agricultural industry by reducing excess products, particularly considering that the administration has outlined a clear intent to support American agriculture.

Though seemingly insignificant, this restructuring would undermine one of the intended purposes of the program: to provide a means for low-income households to access adequate meals that are low-cost and nutritious. In the extreme case, this proposal could hurt households who currently depend on SNAP benefits.

\section{FOOD EXPENDITURES}

As noted, research has shown that SNAP increases the food budgets of those who receive benefits. This is especially true for households whose current food budgets (without SNAP) are lower than what it costs to provide consistent adequate meals.

As previously discussed, Thaler's theory of mental accounting posits that households categorize their sources of income to determine where money should be spent. Since SNAP benefits are limited to food purchases, households can only categorize those benefits for food purchases. From this vantage point, it can be inferred (in the extreme case), that SNAP recipients would place a different value on the portion of 


\section{Featured Articles}

benefits they receive in the form of a food package versus the portion that is allocated on their EBT card. In this way, a household is likely to see the package as reducing the overall amount available to spend on food. This has the effect of reducing their allotment to food expenditures and causes their marginal propensity to consume food to decrease. This would be especially true for individuals who had no use for the products contained in the packages, which may also prompt some households to stop participating all together.

\section{FOOD INSECURITY AND HEALTH}

One possible consequence of changing SNAP in the proposed way is increased food insecurity among households that receive benefits. According to the Council of Economic Advisers (CEA), 14 percent of U.S. households experienced food insecurity in 2014. Further, 40 percent of all food-insecure households had very low food security (CEA 2015). Food insecurity is defined as difficulty in obtaining food or reduced diet quality as a consequence of limited resources. Very low food security is the reduction in food intake due to insufficient resources and a household member experiencing hunger at some point during the year (CEA).

Food insecurity is closely linked with low income and is one of the most significant social determinants of health (Diaz 2018). Households receiving SNAP are likely to be disadvantaged in other ways: they typically include households headed by African Americans and Hispanics, those headed by single women, and those with children and elderly persons. As illustrated in studies of the impacts of the stimulus package's increase to SNAP benefits, a household's expenditures expand with more benefits and decrease with fewer benefits. The proposed changes would cause these households to continue current coping mechanisms that reduce food intake, including skipping meals, negatively impacting their lives in many ways.

Current benefit amounts and the method used by the USDA to calculate those amounts also suggest that the new structure would increase food insecurity. One critical issue the proposed changes do not address is the inadequacy of the Thrifty Food Plan, which serves as the basis for allocation of households' specific benefit amounts. This standard, considered outdated by the CEA, is the cheapest food plan and assumes that all food is consumed at home and made from scratch (Greater Boston Food Bank). The plan is calculated monthly using consumer price index data. However, the plan falls short in its lack of consideration for variations in food pricing across regions, its overestimation of households' consumption of certain items (for example, whole wheat pasta), and its divergence from the palate of an average household.

The CEA reported in 2015 that, although SNAP benefits put more food on the table than households would have without it, current levels are insufficient in sustaining families through the end of the month. In FY 2018, average SNAP benefits per person totaled about $\$ 126$ per month, amounting to about $\$ 1.40$ per person per meal (CBPP 2018). The inability of current benefits to last the whole month was associated with a 10 to 25 percent drop in caloric intake (CEA). This is most harmful to children because 
it can stunt their development and ability to succeed in school. The CEA reports an association between increased disciplinary action and decreased test scores among school-aged children who experience this gap in nutrition-putting their future success and contribution to society in jeopardy.

Low resources and food insecurity may also lead food-insecure households to utilize more public health services. When a household has little income to expend on food, it must stretch its resources. This takes the form of consuming cheaper, unhealthier meals or skipping meals altogether-increasing hospitalization rates and the likelihood of developing chronic illnesses. Low-income households typically delay seeking medical services until cases of emergency and when they do, typically use public hospitals. If they are also uninsured, or receive Medicare or Medicaid, this could potentially cost the government even more as it typically funds public hospitals.

\section{COST OF DISTRIBUTION}

A critical factor in SNAP outcomes is the delivery method used to get benefits to recipients. The Trump administration did not produce a clear plan as to how exactly the proposed food packages would be distributed. It claimed that states would have "substantial flexibility in designing the food box delivery system through existing infrastructure, partnerships, or commercial/retail delivery services" (OMB 2018). However, officials did not outline whether the federal government would provide states the funding necessary to design the system, or whether states would have to come up with that funding on their own.

Existing infrastructure may not be sufficient, warranting the design of a new delivery system. Policymakers must also consider the cost of distribution centers to keep items from spoiling before they reach recipients. The companies that partner with the government to distribute the boxes will not provide their services for free, so labor costs need to also be considered. In addition, a system would need to be developed to track deliveries and pickups.

Having to pick up packages may produce a new undue burden on low-income households, especially for working families-for example, if delivery and pickup times are during work hours, or if a household does not have a vehicle and the distribution center is inconveniently located. Mitigating these concerns may end up costing more than it does to run the program in its current form. This system may create issues similar to those suffered by the commodity distribution program: items may not reach those who need them, the range of products may be limited, and timing issues may arise with distribution.

\section{CONCLUSION}

SNAP is a vital component of the safety net that low-income households depend on, particularly during times of economic hardship. The program continues to be critical in alleviating food insecurity for millions of households, many of which 


\section{Featured Articles}

consist of children, seniors, and persons with disabilities. Though far from perfect, there is no doubt the program has lessened the burdens experienced by low-income households-playing a critical role in reducing the impacts of poverty for recipients. If the changes proposed in the FY 2019 budget request were to be implemented, they would impact the welfare of households by prompting them to change consumption behavior through mental accounting. This could be detrimental to the well-being of low-income individuals, many of whom are already struggling due to insufficient current benefit levels.

\section{REFERENCES}

Beatty, Timothy K.M. and Charlotte J. Tuttle. 2014. "Expenditure Response to Increases in In- Kind Transfers: Evidence from the Supplemental Nutrition Assistance Program." American Journal of Agricultural Economics 97 (2): 390-404. https://doi.org/10.1093/ajae/aau097.

Booker, Brakkton and Dan Charles. 2018. "Republican Farm Bill Calls on Many SNAP Recipients to Work or Go to School." NPR, April 12, 2018. https://www.npr.org/sections/ thesalt/2018/04/12/601900588/republican-farm-bill-calls-on-some- snap-recipients-towork-or-go-to-school.

Center on Budget and Policy Priorities (CBPP). 2018. "A Quick Guide to SNAP Eligibility and Benefits." CBPP, October 16, 2018. https://www.cbpp.org/research/food-assistance/a-quick-guide-tosnap-eligibility-and-benefits.

Claffey, Barbara A. and Stucker, Thomas A. 1982. "The Food Stamp Program." Proceedings of the Academy of Political Science 34 (3): 40-53. https://www.jstor.org/stable/1173727.

Council of Economic Advisers, Executive Office of the President of the United States. 2014. "Long-Term Benefits of the Supplemental Nutrition Assistance Program." Obama White House Archives, December 2015. https://obamawhitehouse.archives.gov/sites/whitehouse.gov/files/ documents/SNAP_report_final_nonembargo.pdf.

Diaz, Stephanie. 2018. "The Effects of Food Insecurity on Health Outcomes and Costs." Healthify, February 8, 2018. https://www.healthify.us/healthify-insights/the-effects-of-food-insecurityon-health-outcomes-and-costs.

Farson Gray, Kelsey, Sarah Fisher, and Sarah Lauffer. 2016. "Characteristics of Supplemental Nutrition Assistance Program Households: Fiscal Year 2015." Prepared by Mathematica Policy Research for the USDA Food and Nutrition Service. https://fns-prod.azureedge.net/sites/default/files/ ops/Characteristics2015-Summary.pdf.

Greater Boston Food Bank. N.d. "The Thrifty Food Plan - SNAP," Greater Boston Food Bank Blog, accessed March 4, 2019. https://www.gbfb.org/2017/09/29/thrifty-food-plan-snap/.

Hoynes, Hilary W. and Schanzenbach, Diane Whitmore. 2007. “Consumption Responses to In-Kind Transfers: Evidence from the Introduction of the Food Stamp Program." American Economic Journal: Applied Economics, American Economic Association 1 (4): 109-39.

Office of Management and Budget (OMB). 2018. "Fiscal Year 2019. Efficient, Effective, Accountable: An American Budget." OMB, DATE. https://www.whitehouse.gov/wp-content/uploads/2018/02/ budget-fy2019.pdf.

Oliveira, Victor. 2018. "The Food Assistance Landscape: FY 2017 Annual Report." EIB-190, U.S. Department of Agriculture, Economic Research Service. https://www.ers.usda.gov/webdocs/ publications/88074/eib-190.pdf?v=0. 
SNAP to Health. N.d. "SNAP in the Farm Bill." New America accessed March 4, 2019. https://www. snaptohealth.org/farm-bill-usda/snap-in-the-farm-bill/.

Thaler, Robert. 1980. "Toward a Positive Theory of Consumer Choice." Journal of Economic Behavior and Organization 1(1): 39-60. http://dx.doi.org/10.1016/0167-2681(80)90051-7.

U.S. Department of Agriculture (USDA). 2018. "A Short History of SNAP." USDA, last modified September 17, 2018. https://www.fns.usda.gov/snap/short-history-snap\#1971.

tros

AHOEFA ANANOUKO is an Master of Public Policy candidate with a passion for service and social justice, and a strong advocate for ethical values in the policy-making process. A refugee-immigrant from Togo, she has strong interest in the impact of policies on low-income and other marginalized communities. While an undergraduate student, she volunteered with the regional Girl Scouts Beyond Bars program, facilitating visits between girls and their incarcerated mothers. She later interned with the Cascade Pacific Council Boy Scouts of America, assisting with life skills education and curriculum management for at-risk youth in local public schools.

\section{ACKNOWLEDGEMENTS}

The author would like to thank Professor Cordes for his guidance on her original paper, as well as friends who lent eyes and ears. She also thanks Professor Barnow for his insights and her editing team for their feedback. In addition, the author thanks her family (especially her mother) who continue to be her motivating force to strive toward her full potential. Her greatest acknowledgment goes to all the people made invisible by our social and political systems, and those affected by harmful policies. 